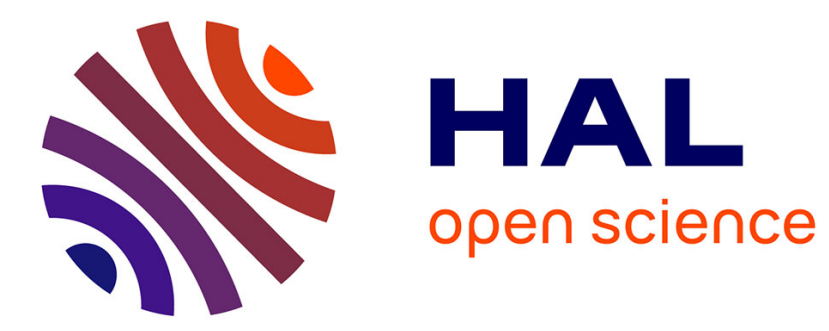

\title{
Calibration of thermocouple-based scanning thermal microscope in active mode $(2 \omega$ method)
}

Tran Phong Nguyen, Laurent Thiery, Sébastien Euphrasie, Séverine Gomès, Bruno Hay, Pascal Vairac

\section{- To cite this version:}

Tran Phong Nguyen, Laurent Thiery, Sébastien Euphrasie, Séverine Gomès, Bruno Hay, et al.. Calibration of thermocouple-based scanning thermal microscope in active mode ( $2 \omega$ method). Review of Scientific Instruments, 2019, 90, pp.114901 (9). hal-02867742

\section{HAL Id: hal-02867742 https://hal.science/hal-02867742}

Submitted on 15 Jun 2020

HAL is a multi-disciplinary open access archive for the deposit and dissemination of scientific research documents, whether they are published or not. The documents may come from teaching and research institutions in France or abroad, or from public or private research centers.
L'archive ouverte pluridisciplinaire HAL, est destinée au dépôt et à la diffusion de documents scientifiques de niveau recherche, publiés ou non, émanant des établissements d'enseignement et de recherche français ou étrangers, des laboratoires publics ou privés. 


\title{
Calibration of thermocouple-based scanning thermal microscope in active mode

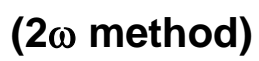

TP Nguyen ${ }^{1}$, L Thiery ${ }^{1}$, S Euphrasie ${ }^{1}$, S Gomès ${ }^{2}$, B Hay ${ }^{3}$ and P Vairac ${ }^{1}$

\author{
${ }^{1}$ Institut FEMTO-ST, UMR 6174, CNRS, ENSMM, Univ. Bourgogne Franche-Comté, 15B, Avenue des \\ Montboucons, 25030 BESANCON Cedex, France \\ ${ }^{2}$ CETHIL UMR5008, Univ. Lyon, CNRS, INSA-Lyon, Univ. Claude Bernard Lyon 1, F-69621, Villeurbanne, \\ France \\ ${ }^{3}$ LNE, 1 rue Gaston Boissier, 75015 Paris, France
}

We present a procedure dedicated to the calibration of a scanning thermal microscopy (SThM) probe operated in active mode and modulated regime especially for the measurement of solid material thermal conductivities. The probe used is a wire microthermocouple mounted on a quartz tuning fork (QTF). Measurements on reference samples are performed successively in vacuum and ambient air conditions revealing a clear difference in the dependence of the thermal interaction between the probe and the sample on the sample properties. Analytical modelling based on the resolution of the heat equation in the wire probe and a description of the thermal interaction using a network of thermal conductances are used to fit experimental data and analyse this difference. We have experimentally verified that the effective thermal contact radius of the probe tip depends on the sample thermal conductivity in ambient conditions whereas it remains constant in vacuum. We have defined the measurement range of the technique based on the decrease of the probe sensitivity at high thermal conductivities. Considering the experimental noise of our electrical device, it is shown that the maximum measurable value of thermal conductivity is near $23 \mathrm{Wm}^{-1} \mathrm{~K}^{-1}$ in vacuum and $37 \mathrm{Wm}^{-1} \mathrm{~K}^{-1}$ in ambient air conditions. Moreover, the lowest uncertainties are obtained for thermal conductivities below $5 \mathrm{Wm}^{-1} \mathrm{~K}^{-}$ ${ }^{1}$ typically.

\section{INTRODUCTION}

In parallel to the growing needs for localized characterization and knowledge improvement in the field of novel material development, scanning thermal microscopy (SThM) is nowadays a major tool for investigating heat transport at scale below one micrometer. Mainly based on an atomic force microscopy (AFM) system equipped with a miniaturized thermal probe, most of the SThM equipment can operate in 
two complementary modes, either in passive mode for surface temperature measurements, ${ }^{1}$ or in active mode for the estimation of thermal parameters such as the thermal conductivity or thermal diffusivity. ${ }^{2}$ The most spread thermal probes are thermoresistive or thermoelectric ones due to their ability to operate in both modes. ${ }^{3}$ Measurements are mainly performed by contacting the local probe to the sample to ensure a lateral resolution which overcomes standard far-field techniques. However, unlike the force interaction used for AFM topographical images, tip-to-surface thermal interactions involve complex coupling effects that link both the probe and the sample characteristics. As a result, both passive and active modes require a thorough analysis to interpret the measurand as a function of the actual surface temperature or the thermal conductivity respectively. ${ }^{4}$

This article is focused on the active mode in which the sensor is self-heated by Joule effect. When a contact occurs, heat dissipates from the probe tip to the cold sample. The resulting variation of the probe temperature provides the relevant data to be interpreted as a variation of the thermal conductance or resistance of the probe-sample system and subsequently the sample thermal conductivity. However, the sample thermal conductance (or the effective thermal conductivity) depends on its internal structure because of the volumetric diffusion process of heat. As a result the variation of the actually measured thermal conductance (the one of the probe-sample system) is also dependent of the sample structure. For instance, measurements of thin films on substrate require taking account of the film/substrate interface and the substrate nature. Let us note that, given the length scale involved in the probe-sample interaction (size of the mechanical contact and tip apex) and in the probed volume, size effects can occur. This is the most critical point that still needs to be addressed even if many efforts have been made for years to correctly evaluate the thermal interaction between a probe tip and different sample structures. Anyway, before being able to operate in any situation, all SThM techniques have to be calibrated so as to know precisely their operating thermal conductivity range, their sensitivity and uncertainty. This is the purpose of the present article in which a rigorous procedure of measurement has been applied on perfectly known samples.

Reference 4 gives an overview of calibration procedures mainly used for commercial resistive probes. Here, the SThM probe used is based on a micro-thermocouple made of two welded wires and is operated in the so-called $2 \omega$ method $^{5}$ as an extension of Roh et al. method. ${ }^{6,7}$ Combined with the use of a quartz tuning fork, such a probe enables controlling the contact force ${ }^{8}$. It also represents an alternative to commercial resistive $S T h M$ probes $^{2}$ while allowing the tip apex temperature to be better mastered and the perturbative effect of the laser ${ }^{9}$ that is observed when SThM is based on an AFM equipped with an optical system of contact force detection, to be avoided. A complete calibration of the passive mode for surface temperature measurement with the same micro-thermocouple is given in reference 10 . 


\section{MODELLING OF THE PROBE RESPONSE}

The thermal model of a micro-thermocouple based on two welded wires is quite simple compared to the complex thermocouple structures involving different metallic layers on insulating cantilever. ${ }^{4}$ Figure 1 depicts the thermocouple probe aspect used in this work. This probe is based on the use of two different Wollaston wires with a core in Platinum $(\mathrm{Pt})$ and $10 \%$ Rhodium-Platinum alloy $\left(\mathrm{Pt} / \mathrm{Rh}_{10 \%}\right)$ respectively. After having removed the silver cladding of $75 \mu \mathrm{m}$ diameter on a length of a few hundred micrometres, both $\mathrm{Pt}$ and $\mathrm{Pt} / \mathrm{Rh}_{10 \%}$ wires are welded by a sparking technique. A focused ion beam (FIB) is used to refine the thermocouple junction whose tip apex radius is in the range 50 to $100 \mathrm{~nm}$. Wollaston wires are available for different core diameters: $0.5 \mu \mathrm{m}, 1.3 \mu \mathrm{m}, 2.5 \mu \mathrm{m}$ or $5 \mu \mathrm{m}$. All these wires have been tested but only results obtained with the $1.3 \mu \mathrm{m}$ diameter wire probe are presented here because it represents the best compromise between robustness and size for a SThM sensor.

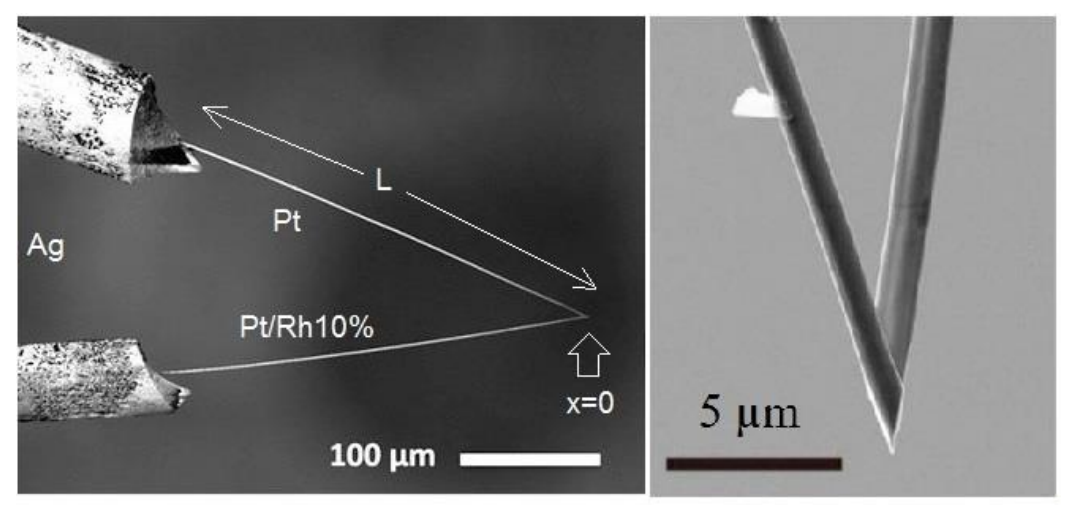

FIG. 1. Scanning electron micrographs of a $1.3 \mu \mathrm{m}$ wire diameter thermocouple.

When an alternating current $I=I_{0} \cos (\omega t)$ is injected in the thermocouple, Joule heating generates a double frequency voltage that corresponds to the Seebeck effect located at the junction. The junction temperature is given by the expression:

$$
\theta_{2 \omega}(0)=\frac{R_{w} I_{0}^{2}}{2} \frac{M_{1 / 2}+\frac{R_{j}}{R_{w}}}{2 \frac{G_{k}}{M}+G}
$$

which corresponds to the magnitude at the junction $\mathrm{x}=0$ of the distribution along the wire of the double frequency temperature $\theta_{2 \omega}(x)$ obtained by solving the heat equation for a thin and long wire heated by joule effect.

It was previously demonstrated by the authors ${ }^{5}$ that, when the temperature distribution differs in both wires, the influence of their physical properties on the junction temperature is negligible. For that reason, only one wire with physical properties calculated as the mean properties between those of $\mathrm{Pt}$ and $\mathrm{Pt} / \mathrm{Rh}_{10 \%}$ 
(see Table 1) is here considered. Besides, all properties and parameters given below are assumed to be independent of temperature.

In equation (1), $R_{j}$ corresponds to a specific electrical resistance, due to an imperfect junction contact that creates a local hot point.

$I_{0}$ is the current magnitude at frequency $\omega$,

$R_{w}=\frac{\sigma L}{S}$ is the wire electrical resistance, $\sigma$ being the wire electrical resistivity, $L$ the wire length and $S$ its cross section.

$G_{k}=\frac{k S}{L}$ is the wire thermal conductance with $k$ the wire thermal conductivity.

$M=\frac{\tanh [m L]}{m L} \quad$ and $\quad M_{1 / 2}=\frac{\tanh [m L / 2]}{m L / 2} \quad$ where $m=\sqrt{\frac{4 h}{k d}+2 i \frac{\omega}{a}} ;$

$d$ is the wire diameter,

$h$ is the heat convection coefficient and $a$ is the wire thermal diffusivity,

$G$ is the tip-to-sample surface thermal conductance $\left(\mathrm{W} \mathrm{K}^{-1}\right)$.

Since the thermoelectric power of $\mathrm{Pt}$ and $\mathrm{Pt} / \mathrm{Rh}_{10 \%}$ couple corresponds to the $\mathrm{S}$ type standard conversion law, the probe thermoelectric voltage is given by:

$$
V_{2 \omega}=\varphi \theta_{2 \omega}(0)
$$

where $\varphi$ is the Seebeck coefficient at the mean temperature of the junction $\theta_{d c}$.

Table I. Probe material characteristics.

\begin{tabular}{|l|c|c|c|}
\hline & Platinum & Platinum-10\% Rhodium & Average \\
\hline Thermal conductivity: $k\left(\mathrm{~W} \mathrm{~m}^{-1} \mathrm{~K}^{-1}\right)$ & 71.6 & 52 & 61.8 \\
\hline Density: $\rho\left(\mathrm{kg} \mathrm{m}^{-3}\right)$ & 21500 & 19970 & 20735 \\
\hline Specific heat $: c\left(\mathrm{~J} \mathrm{~kg}^{-1} \mathrm{~K}^{-1}\right)$ & 133 & 144.1 & 138.55 \\
\hline Electrical resistivity: $\sigma(\Omega \mathrm{m})$ & $9.8110^{-8}$ & $1910^{-8}$ & $14.4110^{-8}$ \\
\hline
\end{tabular}

If the current frequency is far lower than the thermocouple thermal cut-off, one can consider that the steady component equals the double-frequency component so that: $\theta_{d c}=\theta_{2 \omega}(0)$.

Integrating $\theta_{2 \omega}(x)$ along the wire length provides the mean wire temperature:

$$
\overline{\theta_{2 \omega}}=\frac{R_{w} I_{0}^{2}}{2 G_{k}(m L)^{2}} \frac{G\left(1-M_{1 / 2}\right)+G_{k}\left(\frac{R_{j}}{2 R_{W}}(m L)^{2} M_{1 / 2}+2\left(\frac{1}{M}-1\right)\right)}{2 \frac{G_{k}}{M}+G}
$$

from which the well-known $3 \omega$ component of the probe voltage is:

$$
V_{3 \omega}=\alpha R_{w} I_{0} \overline{\theta_{2 \omega}}
$$


where $\alpha$ is the probe temperature coefficient of electrical resistance.

Let us note that in equation (4), coupling effect between harmonics due to the temperature dependence of the wire electrical resistivity $\sigma$ is not taken into account. ${ }^{3}$ However, it has been shown that, for moderate current values, the influence regarding the relevant information for thermal conductivity extraction which is the temperature contrast between no contact and contact remains weak enough to be neglected. ${ }^{11}$ Moreover, the proposed method to identify a thermal conductivity relies on a calibration curve that corrects deviation between theory and experiment.

Fitting the experimental data with such modelling enables the determination of probe parameters. As an example figure 2 shows a comparison between experimental results and simulations for experiments performed under vacuum and ambient air conditions while the probe and the sample do not interact (probe out of contact then $G=0$ ). The $2 \omega$ and $3 \omega$ harmonics of the probe voltage are plotted versus the input ac current $I$ at a frequency of $9 \mathrm{~Hz}$, and the frequency responses are also plotted in a Bode diagram. The best fitting parameters are $L=380 \mu \mathrm{m}, R_{j}=5 \Omega$ and $h=6500 \mathrm{Wm}^{-2} \mathrm{~K}^{-1}$ in ambient air condition.
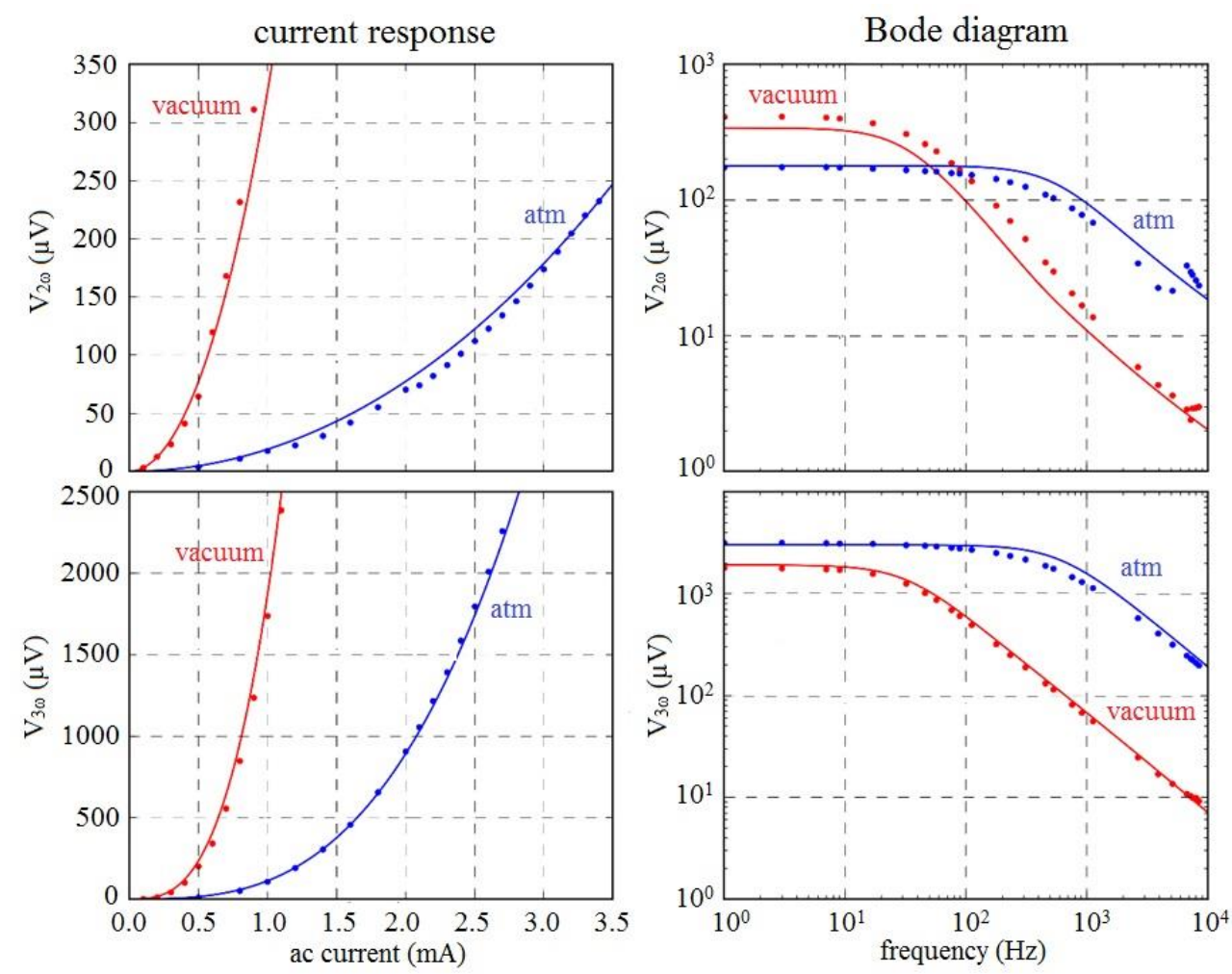

FIG. 2. Comparison of simulations (solid lines) and measurements (dots) of the $2 \omega$ and $3 \omega$ probe voltages for $1.3 \mu \mathrm{m}$ thermocouple probe out of contact in vacuum and ambient air conditions. Supplied ac currents $I_{0}$ for vacuum and ambient conditions of Bode diagram are $1 \mathrm{~mA}$ and $3 \mathrm{~mA}$ respectively. 


\section{THERMAL CONTACT MODELLING}

In conventional SThM analysis, measuring a thermal conductivity requires comparing the probe temperature before the contact with the sample surface with the one during the contact. This can be expressed by the ratio: $\frac{\theta_{n c}-\theta_{c}}{\theta_{c}}$ where $\theta_{n c}$ is the probe $2 \omega$ temperature at thermocouple junction when the probe is far from the sample and $\theta_{c}$ is the temperature when the probe contacts the sample $(G \neq 0)$. Deduced from equations (1) and (2), this ratio is linearly dependent on the thermal conductance $G$ :

$$
\frac{\theta_{n c-} \theta_{c}}{\theta_{c}}=\frac{V_{2 \omega} \text { no contact }-V_{2 \omega \text { contact }}}{V_{2} \omega \text { contact }}=\frac{M G}{2 G_{k}}
$$

In this expression $M$ and $G_{k}$ only depends on the wire geometry and its physical properties and can be calculated using the fitting probe parameters previously determined from figure 2 . As a result, any contact measurement provides a direct estimation of the contact conductance $G$ from which the sample thermal conductivity has to be extracted.

The probe tip geometry enables using a simple thermal contact modelling as already presented in the case of Wollaston wire probe. ${ }^{12}$ When a contact occurs between a hot tip and a sample surface at ambient temperature, the thermal contact can be described by a combination of thermal resistances as shown in figure 3. The resistance of the effective thermal contact $R_{c}$ accounts for the various thermal physical mechanisms contributing to the probe-sample interaction: radiative heat transfer $\left(R_{r a}\right)$, heat transfer by conduction through air $\left(R_{\text {air }}\right)$, through solid contact $\left(R_{s c}\right)$ and through water meniscus $\left(R_{w}\right)$. In the diffusive regime of heat conduction, the spreading or macro-constriction resistance $R_{s}$ is $1 /\left(K b k_{s}\right)$. It depends on the thermal contact radius $b$ and the sample thermal conductivity $k_{s} . K$ is a geometrical factor accounting for the effective spreading within the sample depending on the boundary condition at the contact. In vacuum, heat conduction through water meniscus $\left(R_{w}\right)$ and air $\left(R_{\text {air }}\right)$ become negligible for pressure below 100 Pa. ${ }^{13}$ 


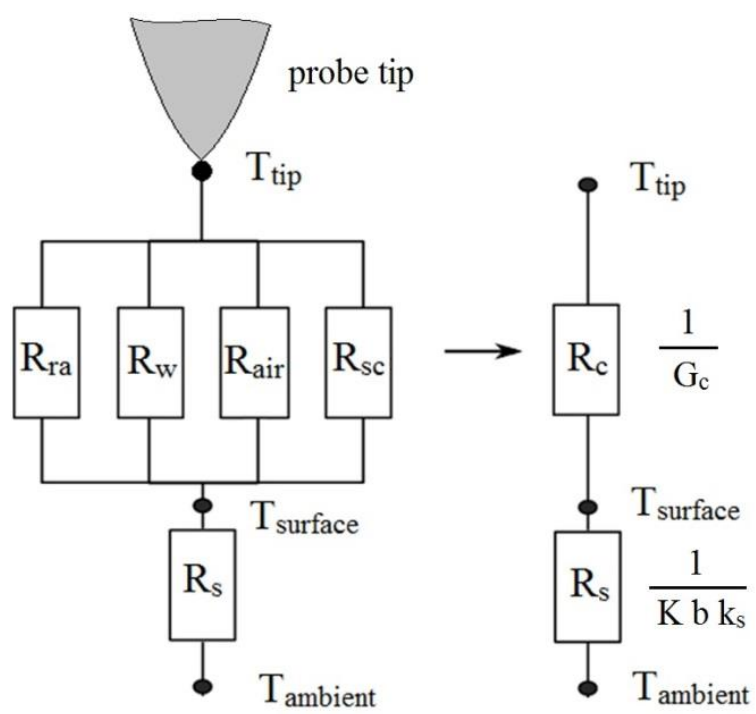

FIG.3. General configuration of heat transfer between a hot tip and a sample surface.

According to this approach, and assuming a constant value $K=2$ (isothermal discoidal contact area), ${ }^{4,14}$ the measured thermal conductance $G$ is expressed by:

$$
\frac{1}{G}=\frac{1}{2 b k_{s}}+\frac{1}{G_{c}}=\frac{1}{G_{s}}+\frac{1}{G_{c}}
$$

Assuming all terms constant, it follows:

$$
\frac{V_{2 \omega \text { contact }}}{V_{2 \omega \text { no contact }}-V_{2 \omega \text { contact }}}=\frac{2 G_{k}}{M}\left(\frac{1}{2 b k_{s}}+\frac{1}{G_{c}}\right)=\frac{A}{k_{s}}+B
$$

where $A$ and $B$ are experimental constants to be extracted from a calibration procedure.

However, in ambient air, some authors suggested that the thermal contact radius $b$ may decrease when the sample thermal conductivity increases. ${ }^{15,4}$ This phenomenon, confirmed by $3 \mathrm{D}$ finite element method simulations, ${ }^{11}$ can be explained by considering that the probe volume over the tip contact contributes to transfer a fraction of the heat through air all around the contact area which inevitably spread. When the sample thermal conductivity increases, the sample spreading resistance decreases so that heat diffuses more efficiently through the mechanical contact which reduces both the tip temperature and the remaining fraction of heat transferred by air conduction. As a result, the thermal contact radius (called $b_{a}$ in this case) decreases following - as a first approximation - a linear dependence versus the inverse of thermal conductivity, leading to the expression:

$$
b_{a}=\frac{\beta}{k_{S}}+b_{0}
$$

$\beta$ and $b_{0}$ being constants that depend on the probe tip geometry and the surrounding media thermal conductivity. Using the same tip-sample equivalent conductance term of expression (6), $1 / 2 b_{a}$ represents 
the slope (derivative) of the thermal resistance $1 / G$ versus $1 / k_{s}$. As a result, taking the integral of $1 / 2 b_{a}$ gives:

$$
\frac{1}{G}=\int \frac{1}{2 b_{a}} d\left(\frac{1}{k_{s}}\right)=C_{1} \ln \left(\frac{1}{k_{s}}+C_{2}\right)+C_{3}
$$

$$
\begin{array}{ll}
\text { Knowing that: } & \frac{1}{G}=\frac{M}{2 G_{k}} \frac{V_{2 \omega \text { contact }}}{V_{2 \omega \text { no contact }}-V_{2} \omega \text { contact }} \\
\text { it can be written that } & \frac{V_{2 \omega \text { contact }}}{V_{2 \omega \text { no contact }-V_{2} \omega \text { contact }}}=A_{a} \ln \left(\frac{1}{k_{s}}+B_{a}\right)+C_{a}
\end{array}
$$

where $A_{a}, B_{a}$ and $C_{a}$ are constants that can be obtained from fitting the experimental measurements with modelling. This difference between vacuum and ambient air conditions will be confirmed in the following results.

\section{EXPERIMENTS AND RESULTS}

In the following calibration procedure, a series of eleven bulk materials of thermal conductivity ranging from 0.1 to $100 \mathrm{Wm}^{-1} \mathrm{~K}^{-1}$ and roughness $\left(R_{m s}\right)$ measured below $20 \mathrm{~nm}$ were chosen. Metals were excluded from study because:

- energy carriers in metals include also electrons contrarily to the other materials where only phonons are mainly involved (except for Si P++ for instance);

- we did not manage to machine them so that their roughness is about few nm;

- surface degradation due to oxidation (except for Si and Ge for which it is difficult to conclude since their high thermal conductivity put them in the lower sensitivity range as shown below, however their roughness being more favourable compared to polished metals).

Material thermal conductivities were calculated from the values of thermal diffusivity, specific heat and density measured respectively by the laser flash method, the differential scanning calorimetry (DSC) and the Archimedean immersion method. ${ }^{16}$ Obtained values are given in Table II.

Prepared samples are cylindrical plates of $10 \mathrm{~mm}$ in diameter and $1 \mathrm{~mm}$ in thickness. In the SThM system presently used, the large size of the piezoelectric stages $(10 \times 10 \mathrm{~cm}$ square $)$ coupled with long range actuators enables testing all the samples at a time.

Table II. List and properties of tested materials.

\begin{tabular}{|c|c|c|c|c|}
\hline Material & $\begin{array}{c}\text { Thermal conductivity } \\
\left(\mathrm{W} \mathrm{m}^{-1} \mathrm{~K}^{-1}\right)\end{array}$ & $\begin{array}{c}\text { Specific heat } \\
\left(\mathrm{J} \mathrm{kg}^{-1} \mathrm{~K}^{-1}\right)\end{array}$ & $\begin{array}{c}\text { Density } \\
\left(\mathrm{kg} \mathrm{m}^{-3}\right)\end{array}$ & $\begin{array}{c}\text { Roughness } \\
\mathrm{R}_{\mathrm{ms}}(\mathrm{nm})\end{array}$ \\
\hline PMMA & 0.187 & 1430 & 1180 & 6.43 \\
\hline POM-C & 0.329 & 1440 & 1400 & 15.7 \\
\hline
\end{tabular}




\begin{tabular}{|c|c|c|c|c|}
\hline Glass & 1.11 & 763 & 2197 & 1.90 \\
\hline Fused $\mathrm{SiO}_{2}$ & 1.28 & 738 & 2190 & 0.73 \\
\hline $\mathrm{ZrO}_{2}$ & 1.95 & 457 & 5855 & 1.58 \\
\hline $\mathrm{TiO}_{2}$ & 9.15 & 698 & 4174 & - \\
\hline $\mathrm{CaF}_{2}$ & 9.17 & - & - & - \\
\hline $\mathrm{Al}_{2} \mathrm{O}_{3}$ & 29.8 & 765 & 3920 & 10.0 \\
\hline Single crystal $\mathrm{Al}_{2} \mathrm{O}_{3}$ & 36.9 & 769 & 4002 & 0.69 \\
\hline $\mathrm{Ge}$ & 52.0 & 310 & 5294 & 0.57 \\
\hline $\mathrm{Si} \mathrm{p++}$ & 93.4 & 712 & 2330 & 1.47 \\
\hline
\end{tabular}

Measurements for all listed samples were performed under primary vacuum (4 Pa) and ambient air. They were repeated 5 times at 5 different locations (given a total of 25 measurements per sample) by recording the $2 \omega$ and $3 \omega$ voltages for the probe far from contact (a few millimetres) and during contact. The contact force was kept constant, and estimated around $100 \mathrm{nN}$. The probe heating current frequency was chosen below the thermocouple thermal cut-off for ensuring a large voltage magnitude, comparable to the dc component. Thanks to the controllable motorized stage of the SThM, the sample position can be predetermined and recorded. A single point measurement lasts 3 seconds of tip-in-contact position to guarantee the thermal stabilization so that the global measuring duration is reduced to about 15 minutes.

\section{A. Vacuum measurements}

In vacuum, the required ac current magnitude is lower than in ambient air to reach the same level of probe temperature. In the following, indicated ac data are RMS values. The supplied current $I_{0}=1 \mathrm{~mA}$ and the chosen frequency is $f=57 \mathrm{~Hz}$. In such conditions the out of contact probe $2 \omega$ voltage $(4 \mathrm{~mm}$ from the surface) is $232 \mu \mathrm{V}$ which corresponds to a temperature magnitude of $39 \mathrm{~K}$.

Figure 4 depicts the mean relative voltage contrast $\left(V_{0}-V_{\text {contact }}\right) / V_{\text {contact }}$ and $V_{\text {contact }} /\left(V_{0}-V_{\text {contact }}\right)$ measured on the different samples and plotted versus the thermal conductivity $k_{s}$ and its inverse $1 / k_{s}$ respectively. The best fit (red line) of experimental data obtained using the present modelling is also reported. 

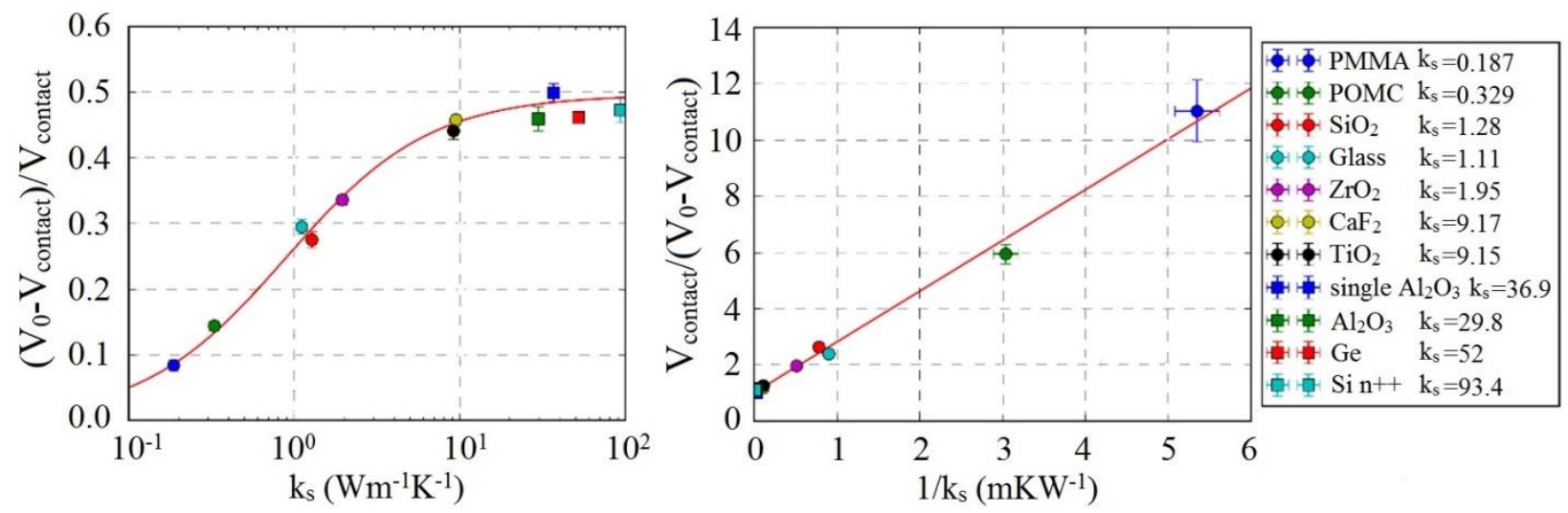

FIG.4. Voltage ratios measured in vacuum as a function of the reference samples thermal conductivity.

Experimental points and fitting curve (red line).

It is interesting to notice that the linear dependence expected from relation (7) is confirmed. Calibration constants $A$ and $B$, their standard deviation $\sigma$ as well as the linear correlation factor $R$ associated to the linear fitting of experimental data are given in Table III.

Table III. Constants $A$ and $B$ in eq. (7) and statistical parameters corresponding to the linear fit of experimental data for vacuum measurements.

\begin{tabular}{|c|c|c|c|c|c|}
\hline Parameters of the linear fit & $A$ & $\sigma_{A}$ & $B$ & $\sigma_{B}$ & $R^{2}$ \\
\hline Values & 1.8030 & 0.01714 & 1.0181 & 0.03316 & 0.9897 \\
\hline
\end{tabular}

Knowing $M, G_{k}, A$ and $B$, the thermal contact conductance can be plotted versus the sample thermal conductivity or its inverse and the values of the thermal contact radius $b$ and the contact conductance $G_{c}$, which are assumed constant can be calculated. Thermal contact conductance values are depicted in figure 5 with associated uncertainty bars representing the standard uncertainty deduced from the standard deviation of the mean. In the present case, $b=22.9 \pm 5 \mathrm{~nm}$ and $G_{c}=8.15 \pm 1.3 \times 10^{-7} \mathrm{~W} \mathrm{~K}^{-1}$. This means that for these different samples, the contact conditions remain unchanged. 

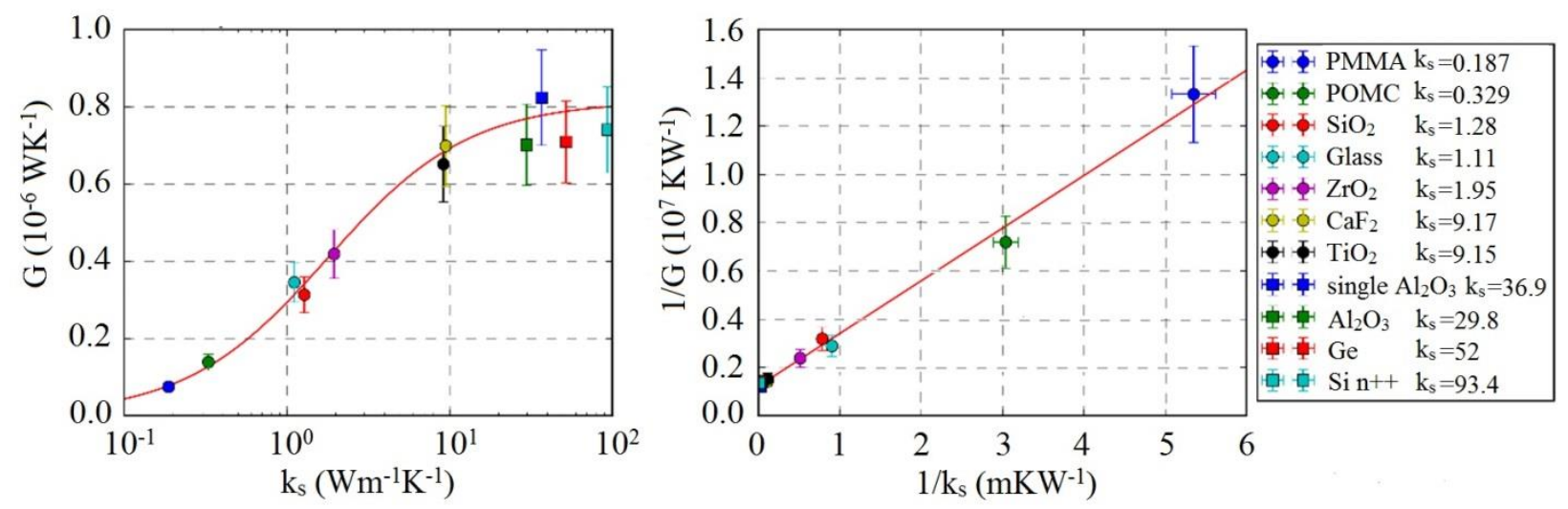

FIG.5. Resulting thermal contact conductance versus the samples thermal conductivity measured in vacuum.

Using the Hertz theory of contact between a sphere and a plane surface, an estimation of the contact radius gives $11 \mathrm{~nm}$ on the softer sample (PMMA) and $3 \mathrm{~nm}$ on the harder (monocrystalline $\mathrm{Al}_{2} \mathrm{O}_{3}$ ) far below $23 \mathrm{~nm}$ extracted from experiment. This was already observed by some authors, the most consistent reason may be the degraded tip shape and an underestimated contact force ${ }^{17}$.

\section{B. Ambient air measurements}

Following the same measurement procedure, except the magnitude of the heating current $I_{0}$ of $3 \mathrm{~mA}$ here, the out of contact probe $2 \omega$ voltage is $162 \mu \mathrm{V}$ corresponding to a temperature magnitude of $27 \mathrm{~K}$. Contrary to vacuum conditions and as depicted in figure 6 , it is observed that there is no linearity dependence between $V_{\text {contact }} /\left(V_{0}-V_{\text {contact }}\right)$ and $1 / k_{s}$.
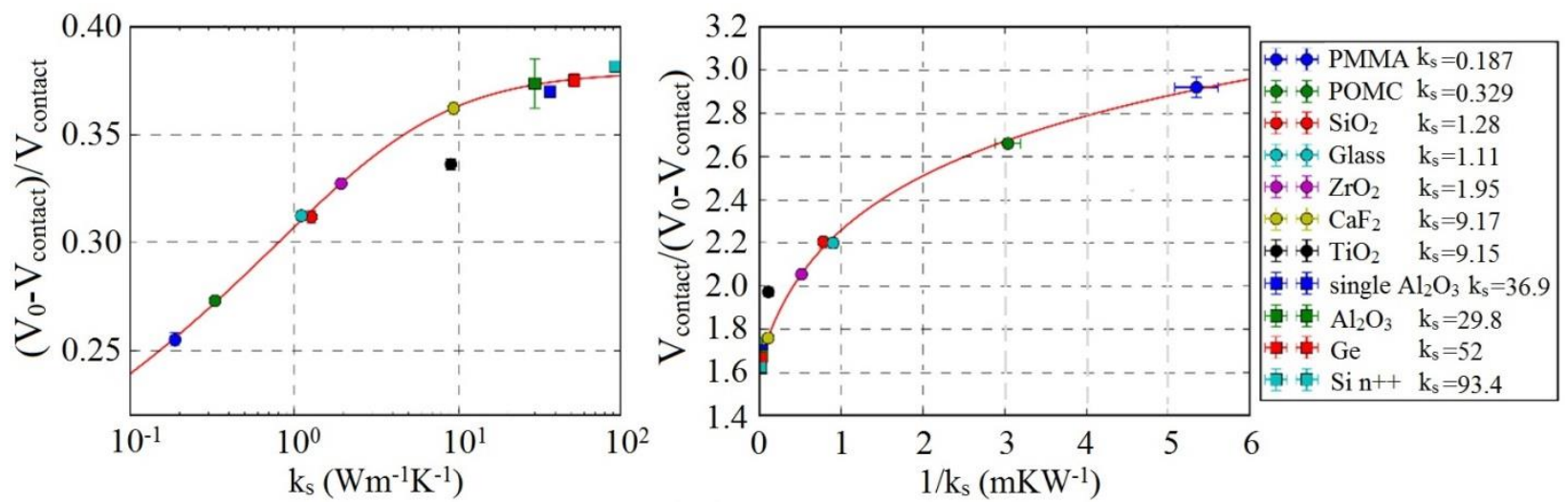

FIG.6. Voltage contrast ratios measured in ambient air. Experimental points and fitting curve (red line).

As a consequence, a non-linear fitting of the experimental data corresponding to expression (11) is performed, giving the resulting red lines in figure 6. 
Calibration constants $A_{a}, B_{a}$ and $C_{a}$ of equation (11) with their main statistical parameters (standard deviation $\sigma$ and correlation factor $R$ ) are given in Table IV.

Table IV. Fitting constants $A_{a}, B_{a}$ and $C_{a}$ for ambient air measurements and their statistical parameters.

\begin{tabular}{|c|c|c|c|c|c|c|c|}
\hline Parameters of the fit & $A_{a}$ & $\sigma_{A a}$ & $B_{a}$ & $\sigma_{B a}$ & $C_{a}$ & $\sigma_{C a}$ & $R^{2}$ \\
\hline Values & 0.4502 & 0.2053 & 0.3362 & 0.4140 & 2.1273 & 0.2849 & 0.9912 \\
\hline
\end{tabular}

Coupling equations (10) and (11) give access to the variation of the thermal contact conductance versus $k_{s}$. Results are depicted in figure 7 where thermal contact conductance values are plotted with their uncertainty bars (standard uncertainty) as a function of thermal conductivity or its inverse.
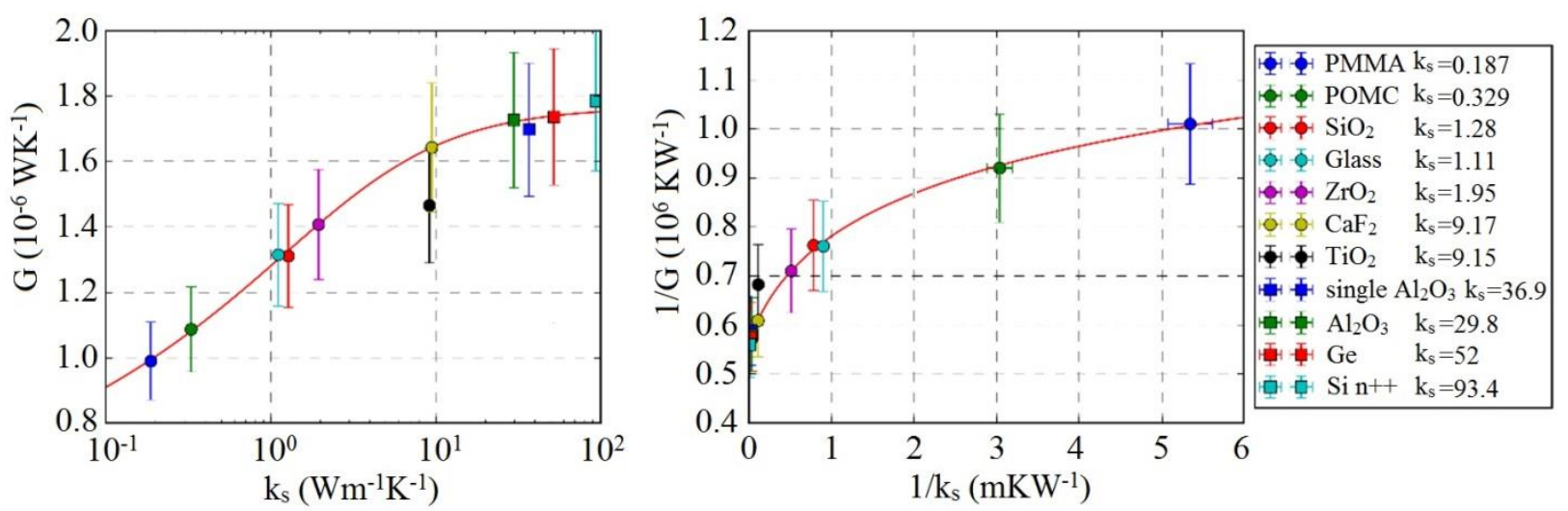

FIG.7. Resulting thermal contact conductances versus the samples thermal conductivity measured in ambient air.

By combining expressions (8) to (11), the constants $b_{0}$ and $\beta$ can be calculated:

$$
b_{0}=\frac{B_{a} G_{k}}{A_{a} M}=1.0810^{-6} \mathrm{~m} \quad \text { and } \quad \beta=\frac{G_{k}}{A_{a} M}=3.2110^{-6} \mathrm{~W} \mathrm{~K}^{-1} .
$$

The sample spreading resistance or conductance is deduced from:

$$
G_{S}=2\left(\beta+b_{0} k_{s}\right)
$$

and subsequently the total contact conductance in air $G_{c}$, using expression (6).

\section{RESULTS ANALYSIS AND MEASUREMENT LIMITS}

Previous results have shown that a great difference remains between vacuum and ambient air measurements. In vacuum condition, measurements seem to confirm that contact radius and the contact conductance are constant whatever the sample. We surmise that this is mainly due to the low surface roughness and a reproducible probe contact force. In ambient conditions, air conduction plays a dominant role as shown in figure $8 \mathrm{a}$ where the $2 \omega$ probe temperature magnitude is affected at distances that exceed 
$100 \mu \mathrm{m}$ from a silicon sample surface. At shorter distances, the magnitude of the equivalent conductance $G$ measured in vacuum and air are clearly different showing a strong difference in the probe-sample interaction between both experimental environmental conditions. No heat transfer between the probe and the sample is detected before the contact in vacuum (figure $8 \mathrm{~b}$ ) confirming the assumption of negligible gas conduction at this pressure.
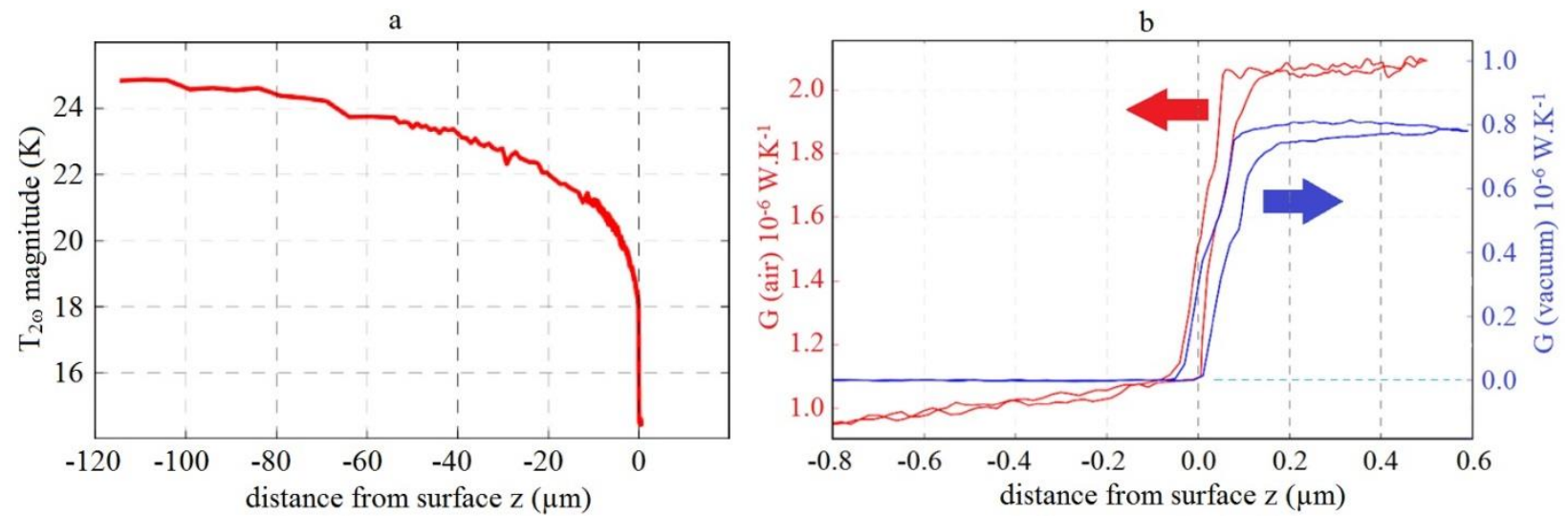

FIG.8. Effects of the probe tip distance to the surface of a silicon wafer on the $2 \omega$ temperature magnitude when experiments are performed in ambient air (a), and on the measured thermal conductance for experiments in ambient air (red colour) and vacuum (blue colour) (b).

In these measurements where temperature elevation remains very moderate, radiative heat transfer stays negligible and the heat transfer through the water meniscus can be included in the mechanical contact conductance $G_{c}$. Then only two thermal resistances are considered: $R_{c}$ and $R_{s}$ describing the contact and the sample spreading effects respectively. Vacuum measurements have shown that both quantities remain unchanged when varying the sample thermal conductivity. In ambient air, it is worthy to consider that additional contributions are superimposed: a contact through air and a spreading component that appears in the relation between contact thermal radius $b_{a}$ and $k_{s}$. As described in figure 9 , it is assumed that the solid-solid contact component in ambient air $\left(G_{c s}\right)$ equals the contact conductance value of $8.1510^{-7} \mathrm{WK}^{-1}$ measured in vacuum, and that the vacuum spreading conductance corresponds to the pure solid spreading component in air $\left(G_{s s}\right)$. 


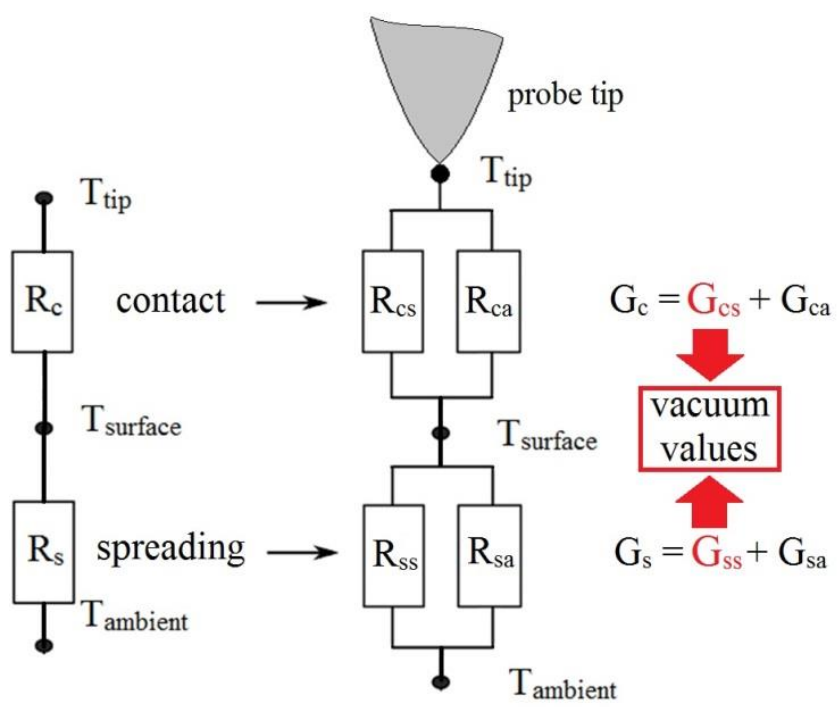

FIG.9. Modified tip-surface heat transfer assuming superimposed vacuum and air contributions.

Indeed, we assume constant $G_{c s}$ because it has been found experimentally constant from vacuum measurements when $b$ is assumed constant. With such assumptions, it appears from the good fitting between experimental data and modelling that the impact of the thermal solid-solid conductance variation, which is related to the boundary resistance at the solid-solid contact, can be neglected.

In ambient air conditions, $G$ becomes $G_{a}$ and expression (6) gives:

$$
\frac{1}{G_{a}}=\frac{1}{G_{c S}+G_{c a}}+\frac{1}{G_{s S}+G_{s a}}
$$

Consequently, the contribution of air conduction $G_{c a}$ corresponds to the subtraction between the total contact conductance in air $G_{c}$ and the solid conductance $G_{c s}$. Figure 10a depicts these contributions versus $1 / k_{s}$. Following the same approach, the spreading conductance $G_{s}$ is the sum of the vacuum contribution called $G_{s s}$ (spreading sample) and the air contribution $G_{s a}$ (spreading air), the latter being deduced from the others. Figure $10 \mathrm{~b}$ depicts thermal contact radius $b_{a}$ extracted from experiments versus $1 / k_{s}$. 


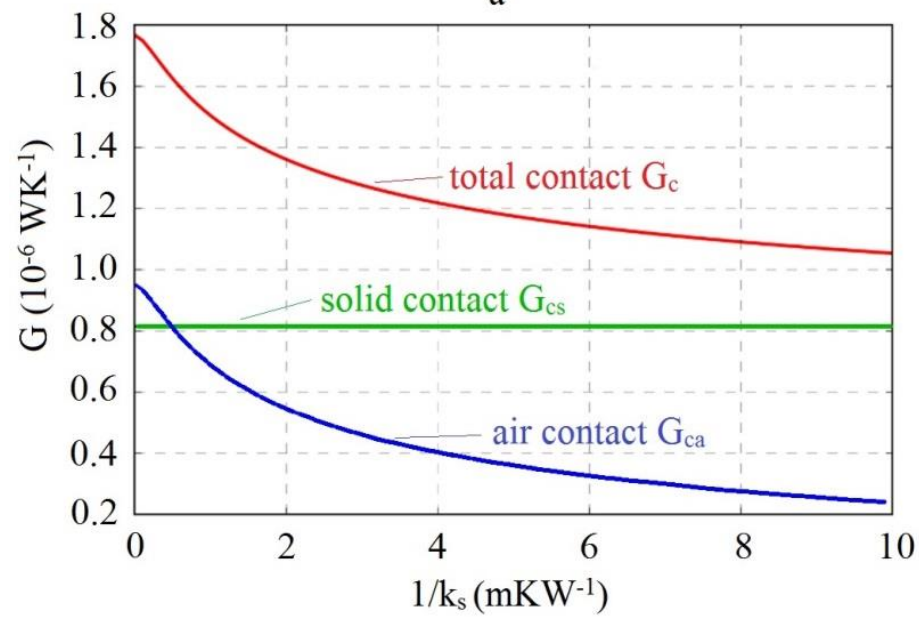

$\mathrm{b}$

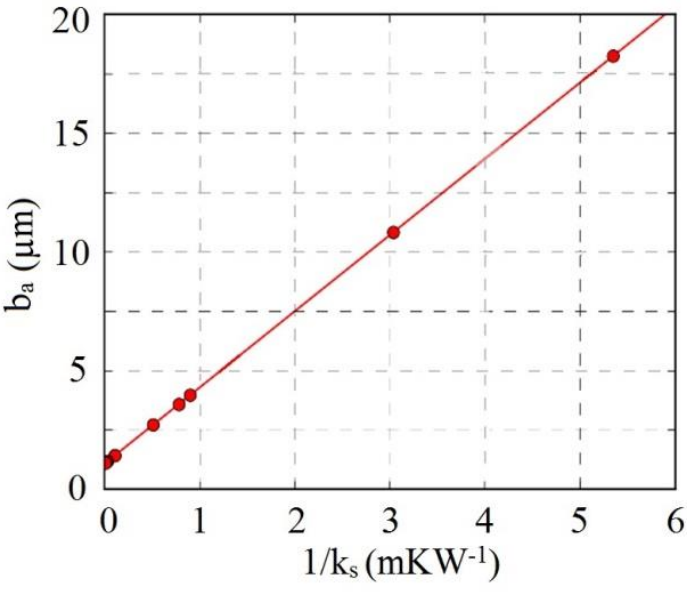

FIG.10. Effects of the thermal conductivity on the contact conductance $G$ (a) and the contact thermal radius $b_{a}(\mathrm{~b})$.

The experimental validation of a non-linear relationship between $1 / G_{s}$ and $1 / k_{s}$ results in a contact thermal radius that reaches some tens of micrometres for the lowest sample thermal conductivities. Inversely, the contact efficiency, through $G_{c}$, is improved when the sample thermal conductivity increases. Table 5 presents all the conductance values extracted from this analysis, on tested samples having the minimal and the maximal thermal conductivity: PMMA and doped silicon respectively.

Table V. Synthesis of the different thermal conductance obtained for PMMA and doped silicon ( $\mathrm{Si} \mathrm{n++})$ under vacuum and air ( $\mathrm{v}$ index indicates vacuum values).

\begin{tabular}{|c|c|c|c|}
\hline Environment & $\begin{array}{c}\text { Thermal conductance } \\
\qquad\left(10^{-8} \mathrm{WK}^{-1}\right)\end{array}$ & $\begin{array}{c}\text { PMMA } \\
\left(k_{s}=0.187 \mathrm{Wm}^{-1} \mathrm{~K}^{-1}\right)\end{array}$ & $\begin{array}{c}\text { Si n++ } \\
\left(k_{s}=93.4 \mathrm{Wm}^{-1} \mathrm{~K}^{-1}\right)\end{array}$ \\
\hline \multirow{3}{*}{ Vacuum } & $G_{v}$ & \multirow{3}{*}{$\begin{array}{c}7.5 \\
81.5 \\
8.3\end{array}$} & 74.5 \\
\hline & $G_{c v}$ & & 81.5 \\
\hline & $G_{s v}$ & & 811 \\
\hline \multirow{7}{*}{ Air } & $G_{a}$ & 98.9 & 178 \\
\hline & $G_{c}$ & $116 \quad(100 \%)$ & $180 \quad(100 \%)$ \\
\hline & $G_{c s}=G_{c v}$ & $81.5 \quad(70 \%)$ & $81.5 \quad(45 \%)$ \\
\hline & $G_{c a}=G_{c}-G_{c s}$ & $(30 \%)$ & $98.5 \quad(55 \%)$ \\
\hline & $G_{s}$ & $682 \quad(100 \%)$ & $20811 \quad(100 \%)$ \\
\hline & $G_{s s}=G_{s v}$ & $(2 \%)$ & $(4 \%)$ \\
\hline & $G_{s a}=G_{s}-G_{s s}$ & $(98 \%)$ & $(96 \%)$ \\
\hline
\end{tabular}


These results show that the air contribution is preponderant on sample spreading effect so that the pure solid contact contribution stays rather negligible. On the contrary, the contribution of air in the contact conductance is in the range of 30 to $55 \%$ from the lowest to the highest thermal conductivity value.

Besides, air contributes to reduce the dynamic range of the technique and therefore its sensitivity (the variation of $G$ being more than five times lower, for the same variation of thermal conductivity, in air rather than in vacuum) as shown by arrows in Table 5. However, the efficiency of the probe-sample heat transfer being increased, it is less roughness and force dependent, so that the uncertainty associated to the probe voltage measurement is reduced. Indeed, the extracted noise from experiments, expressed as a relative uncertainty on the probe voltage contrast: $\frac{V_{2 \omega} \text { contact }}{V_{2 \omega} \omega \text { no contact }-V_{2} \omega \text { contact }}$, gives $N_{v}=7.6 \%$ in vacuum and $N_{a}=2.1 \%$ in air.

These values are calculated by propagating the measured standard uncertainty of the probe voltage $V_{2 \omega}$ in contact, the out of contact voltage being stable enough to be assumed as a constant value. The thermal conductivity measurement limit can then be estimated by comparing the measurement threshold of the curves: $\frac{V_{2 \omega \text { contact }}}{V_{2 \omega} \omega \text { no contact }-V_{2} \omega \text { contact }}=f\left(k_{s}\right)$ in vacuum and in air with $N_{v}$ and $N_{a}$.

Indeed, for large thermal conductivities, the detection threshold is limited by the experimental noise level. For $k_{s} \rightarrow+\infty$ typically, the voltage contrast of equations (7) and (11) gives: $B$ and $A_{a} \ln B_{a}+C_{a}$ for vacuum and air environment respectively, which correspond to the theoretical thresholds without noise.

At a maximum value $k_{s}=k_{\max }$, the experimental voltage contrast reaches the detection threshold to be compared with $\left(\frac{A}{k_{\max }}+B\right)$ in vacuum and $A_{a} \ln \left(\frac{1}{k_{\max +B_{a}}}\right)+C_{a}$ in air.

Measurements in vacuum and air become possible in the conditions:

$$
\frac{\left(\frac{A}{k_{\max }}+B\right)-B}{B}>N_{v} \quad \text { and } \quad \frac{A \ln \left(\frac{1}{k_{\max }}+B\right)+C-(A \ln B+C)}{A \ln B+C}>N_{a} \text { respectively. }
$$

This gives the limit of measurable thermal conductivity in vacuum:

$$
k_{s}<\frac{A}{B N_{v}}=23.3 \mathrm{~W} \mathrm{~m}^{-1} \mathrm{~K}^{-1}
$$

And the limit of measurable thermal conductivity in ambient air:

$$
k_{S}<\left(e^{\frac{\left(1+N_{a}\right)(A \ln B+C)-C}{A}}-B\right)^{-1}=37.5 W m^{-1} K^{-1}
$$

This means that there is no possibility to measure a thermal conductivity above these values. Below these limits, the question of reliability can be addressed by a Monte Carlo error analysis ${ }^{18}$. Considering the experimental results of the present calibration, the method consists in generating random dataset samples 5000 in the present case - for each reference sample (PMMA, POMC etc...) following its representative 
normal distribution (standard deviation, mean...) of the input measured data ( $V_{2 \omega}$ in contact and thermal conductivities). These random datasets based on the real data can represent the physical properties of the calibration (probe-sample interactions), noise levels and sensitivity of the whole system. Fitting parameters ( $A, B$ in vacuum and $A_{a}, B_{a}$ and $C_{a}$ in air) are then deduced for each of the 5000 data set to provide their statistical consistency. The resulting confidence band shows that the best results are obtained for thermal conductivities below $5 \mathrm{Wm}^{-1} \mathrm{~K}^{-1}$ typically, with a relative error estimated to $18 \%$ in vacuum and $24 \%$ in ambient air. Above $5 \mathrm{Wm}^{-1} \mathrm{~K}^{-1}$, the relative error abruptly increases and exceeds $100 \%$.

\section{CONCLUSION AND PERSPECTIVES}

The proposed calibration procedure for the thermal conductivity measurement of a thermocouple SThM probe is based on bulk non-metallic samples of controlled surface roughness in order to avoid roughness related artefacts. It clearly appears a fundamental difference between vacuum and ambient air measurement conditions. In the latter, the non-linearity between the thermal resistance $(1 / G)$ versus the inverse of thermal conductivity of the sample is confirmed. This also demonstrates that, in ambient pressure, the thermal contact radius can extend to values of several micrometers when the sample thermal conductivity decreases. In vacuum, the thermal contact radius remains constant but larger than the contact radius given by the Hertz theory, probably due to a degradation of the tip geometry and its non spherical shape.

It must be noticed that thermal the contact radius differs from the lateral thermal resolution of the probe that was estimated to be around 150 to $200 \mathrm{~nm}$ whatever the pressure ${ }^{11}$. The lateral thermal resolution of a thermal probe still needs to be conveniently identified and defined. In addition to the highlighting of the available thermal conductivity measurement range for the present SThM technique, a simple analysis of measurement uncertainties leads to conclude that the best relative uncertainty is $15 \%$ for measured thermal conductivity below $5 \mathrm{Wm}^{-1} \mathrm{~K}^{-1}$. Above this value, the uncertainty increases dramatically.

It must be mentioned however that uncontrolled parameters related to the samples themselves have a clear influence on the relative uncertainty since roughness, hardness, hydrophobicity, oxidation, etc... generate measurements deviations that were taken into account in the present analysis. This represents the difference between an apparent thermal conductance and the actual sample thermal conductivity that must be deduced.

Finally, the only way to reduce the uncertainties of the system is to optimize the signal-to-noise ratio by increasing the input current into the probe and reducing electromagnetic disturbances on the thermoelectric voltage; the increase of Seebeck coefficient with a new couple represents a possible way to explore. 


\section{ACKNOWLEDGMENTS}

This work has received funding from the European Union Seventh Framework Program FP7-NMP-2013LARGE-7 under GA No. 604668 Project QUANTIHEAT.

\section{REFERENCES}

1. A. Bontempi, L. Thiery, D. Teyssieux, D. Briand and P. Vairac, Rev. Sci. Instrum. 84, 103703 (2013).

2. A. Bontempi, T.P. Nguyen, R. Salut, L. Thiery, D. Teyssieux and P. Vairac, Rev. Sci. Instrum. 87, 063702 (2016); doi: 10.1063/1.4952958.

3. S. Gomes and S. Lefevre, in Advanced Techniques and Applications on Scanning Probe Microscopy, edited by F. H. Lei (Research Signpost), 157-195 (2008).

4. S. Gomes, A. Assy and P.O. Chapuis, Phys. Status Solid A 212, 3, 477-494 (2015).

5. L. Thiery, E. Gavignet and B. Cretin, Rev. Sci. Instrum. 80, 034901 (2009).

6. H. H. Roh, J. S. Lee, D. L. Kim, J. Park, K. Kim, O. Kwon, S. H. Park, Y., K. Choi, and A. Majumdar, J. Vac. Sci. Technol. B 24, 2398 (2006)_.

7. H. H. Roh, J. S. Lee, D. L. Kim, J. Park, K. Kim, O. Kwon, S. H. Park, Y., K. Choi, and A. Majumdar, J. Vac. Sci. Technol. B 24, 2405 (2006).

8. A. Bontempi, D. Teyssieux, J.M. Friedt, L. Thiery, D. Hermelin, and P. Vairac, Appl. Phys. Lett. 105, 154104 (2014).

9. L. Ramiandrisoa, A. Allard, Y. Joumani, B. Hay and S. Gomès, Rev. Sci. Instrum. 88, 125115 (2017).

10. TP Nguyen ${ }^{1}, \mathrm{~L}$ Thiery ${ }^{1}, \mathrm{~S}$ Euphrasie ${ }^{1}, \mathrm{E} \mathrm{Lemaire}^{2}, \mathrm{~S} \mathrm{Khan}^{2}, \mathrm{D}$ Briand $^{2}, \mathrm{~L}_{\text {Aigouy }}{ }^{3}, \mathrm{~S} \mathrm{Gomes}^{4}$ and $\mathrm{P}$ Vairac $^{1}$, J. Heat Transfer 141(7), 071601 (2019).

11. Tran Phong Nguyen, Advances in quantitative micro/nanoscale thermometry using scanning thermal microscopy, PhD report, Université de Bourgogne Franche-Comté, 2018.

12. S. Lefevre, S. Volz, P.O. Chapuis, Int. J. Heat and Mass Tranf. 49, 251-258 (2006).

13. J. Lee, T. L. Wright, M. R. Abel, E. O. Sunden, A. Marchenkov, S. Graham and W. P. King, J. Appl. Phys. 101, 014906 (2007).

14. M. Yovanovich and E. Marotta, Thermal spreading and contact resistances, in Heat Transfer Handbook, vol 1, Wiley, Hoboken, 261-394 (2003).

15. S. Lefevre and S. Volz, Rev. Sci Instrum.76, 033701 (2005).

16. B. Hay, J. Hameury, N. Fleurence, P. Lacipiere, M. Grelard, V. Scoarnec and G. Davee, Int. J. Thermophys, 35(9-10), 1712-1724 (2014).

17. A. Assy, S. Gomes, Appl. Phys. Lett. 107, 043105 (2015).

18. L. Ramiandrisoa, A. Allard, B. Hay and S. Gomes, Meas. Sci. Technol. 28 (11), 115010 (2017). 


\section{Figure captions}

FIG. 1. Scanning electron micrographs of a $1.3 \mu \mathrm{m}$ wire diameter thermocouple.

FIG. 2. Comparison of simulations (solid lines) and measurements (dots) of the $2 \omega$ and $3 \omega$ probe voltages for $1.3 \mu \mathrm{m}$ thermocouple probe out of contact in vacuum and ambient air conditions. Supplied ac currents $I_{0}$ for vacuum and ambient conditions of Bode diagram are $1 \mathrm{~mA}$ and $3 \mathrm{~mA}$ respectively.

FIG.3. General configuration of heat transfer between a hot tip and a sample surface.

FIG.4. Voltage ratios measured in vacuum as a function of the reference samples thermal conductivity. Experimental points and fitting curve (red line).

FIG.5. Resulting thermal contact conductance versus the samples thermal conductivity measured in vacuum.

FIG.6. Voltage contrast ratios measured in ambient air. Experimental points and fitting curve (red line).

FIG.7. Resulting thermal contact conductances versus the samples thermal conductivity measured in ambient air.

FIG.8. Effects of the probe tip distance to the surface of a silicon wafer on the $2 \omega$ temperature magnitude when experiments are performed in ambient air (a), and on the measured thermal conductance for experiments in ambient air (red colour) and vacuum (blue colour) (b).

FIG.9. Modified tip-surface heat transfer assuming superimposed vacuum and air contributions.

FIG.10. Effects of the thermal conductivity on the contact conductance $G$ (a) and the contact thermal radius $b_{a}(\mathrm{~b})$. 


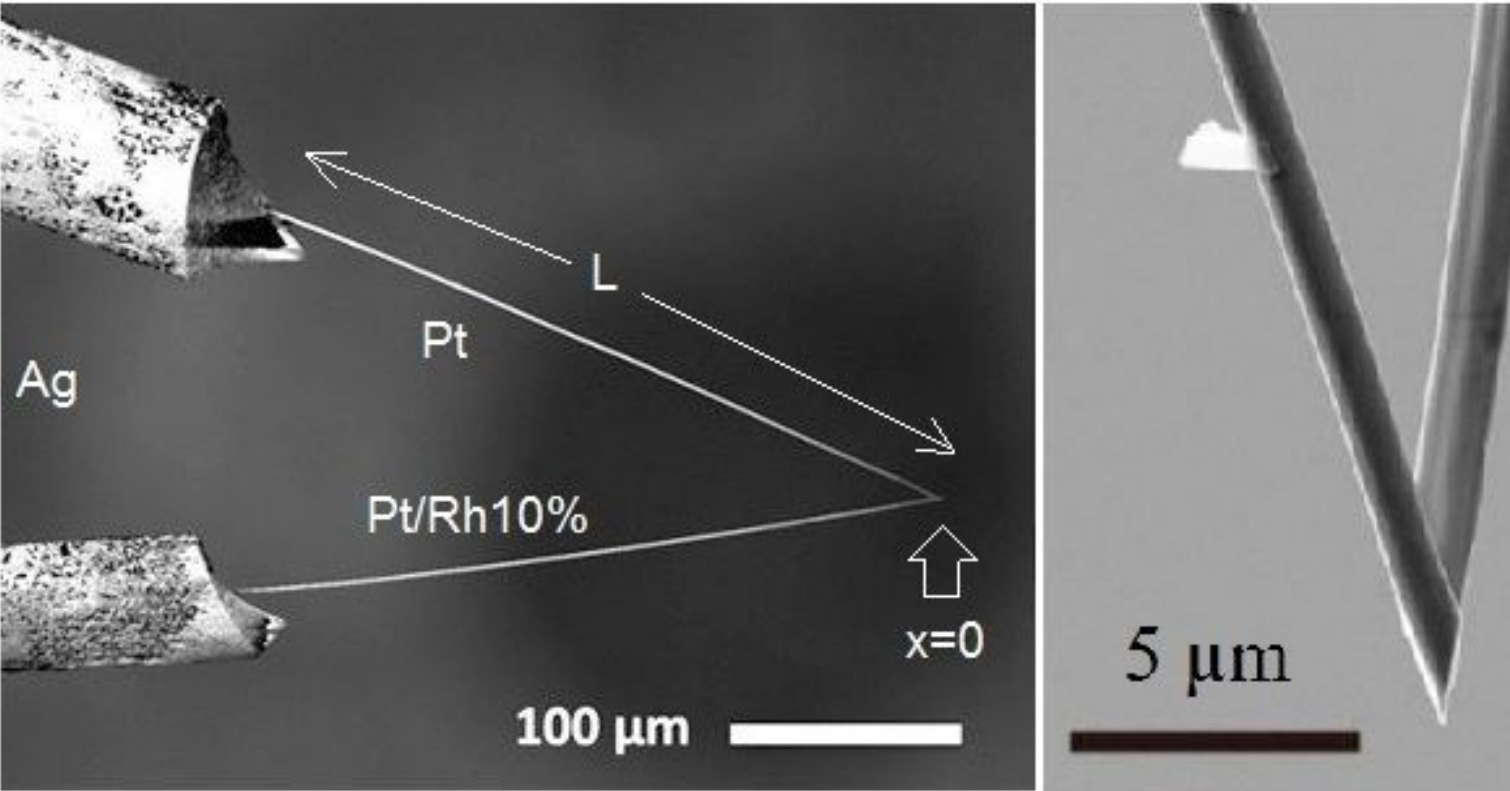




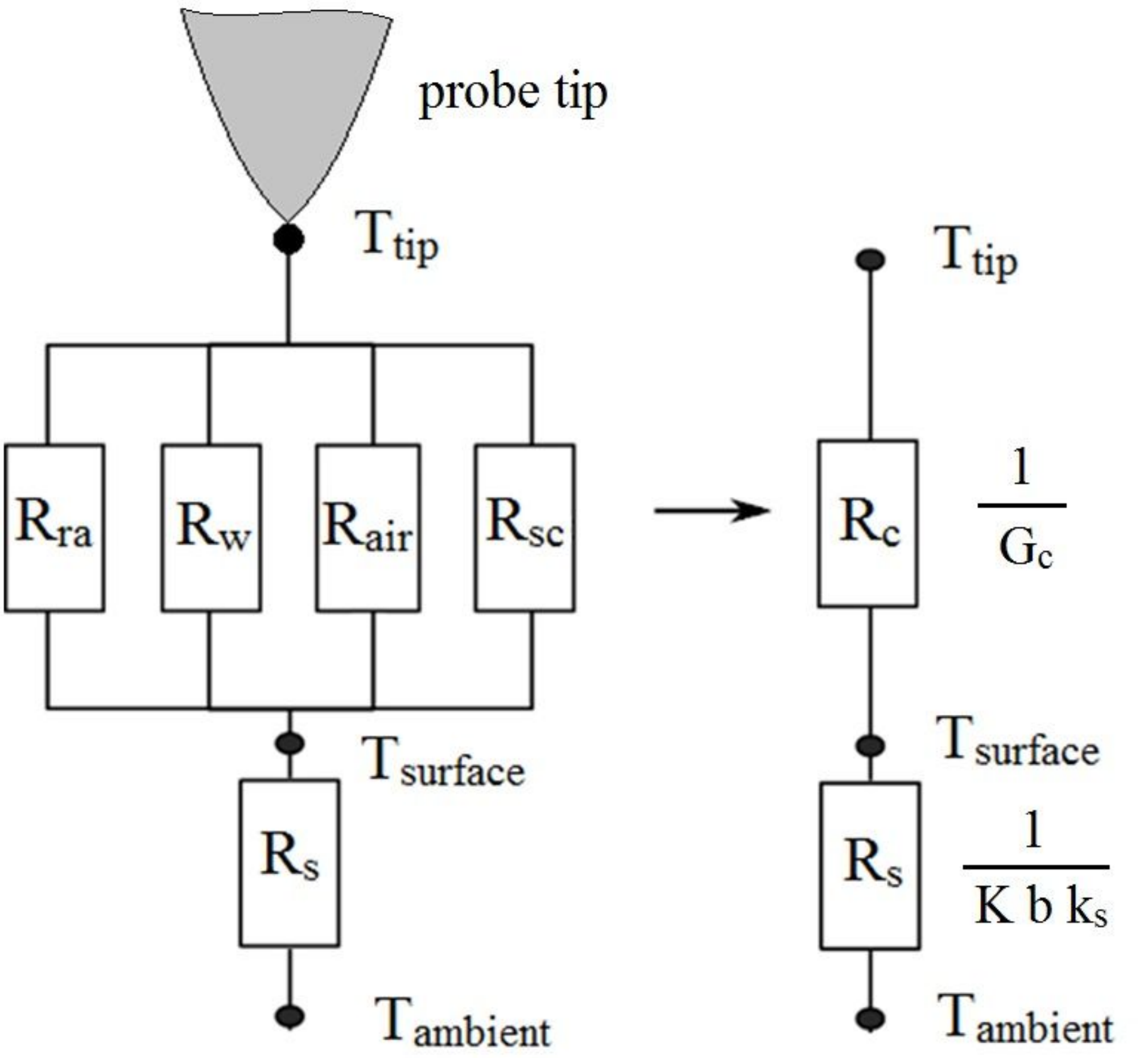




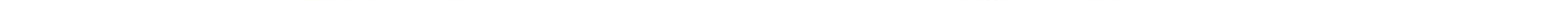




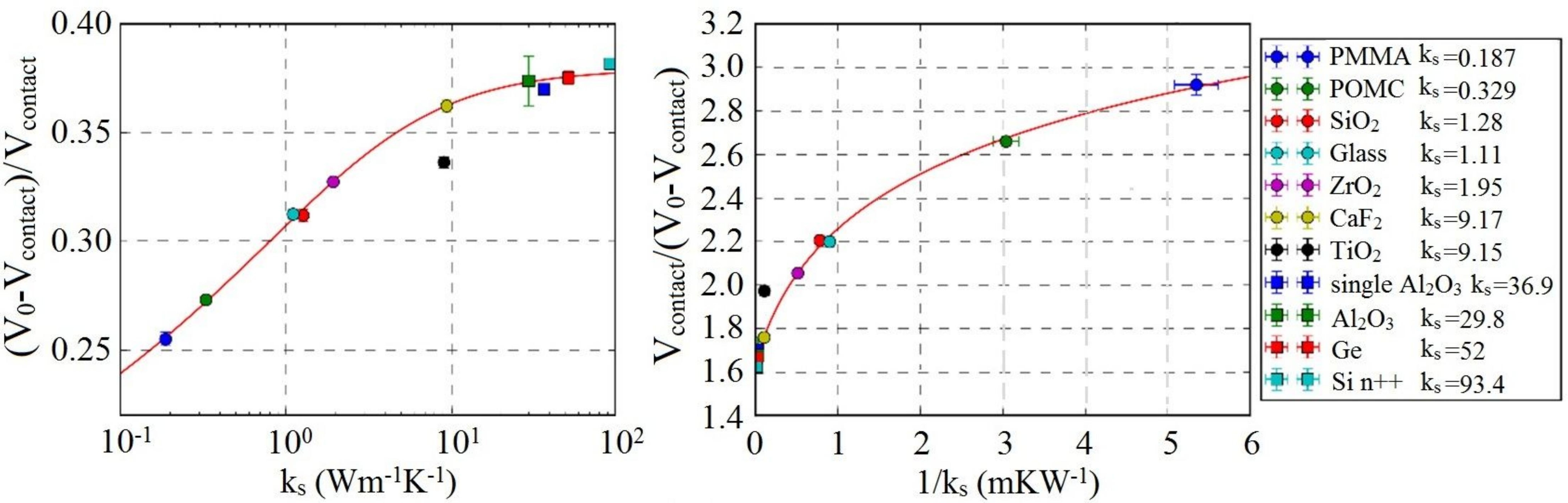








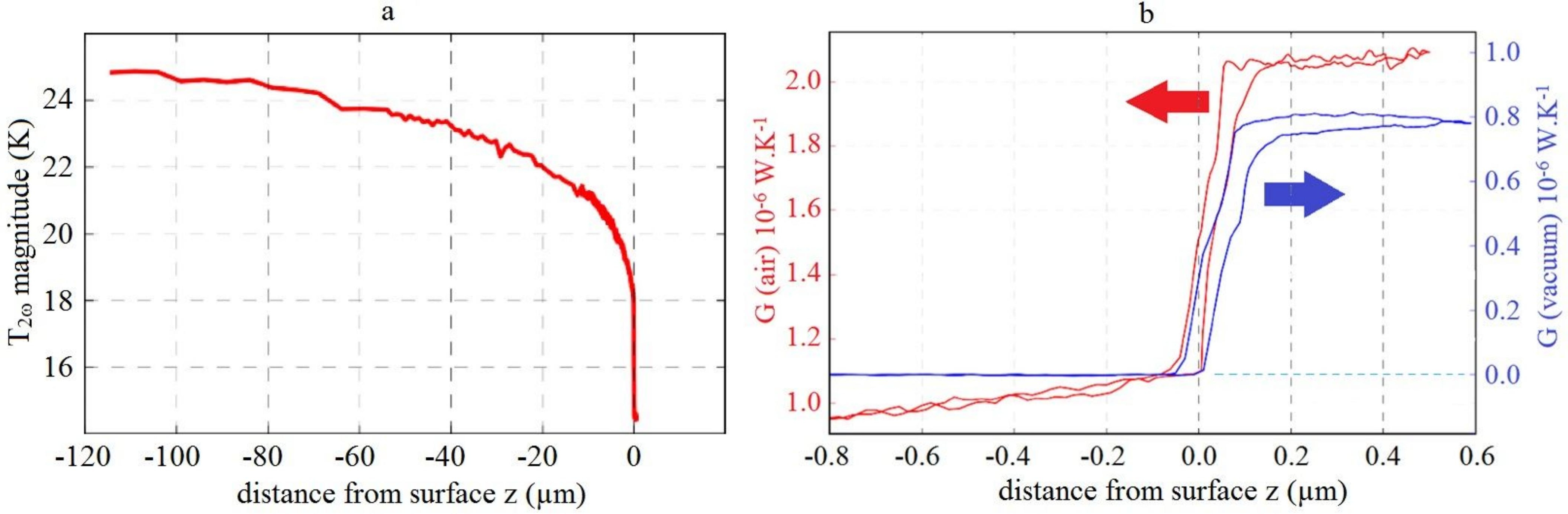

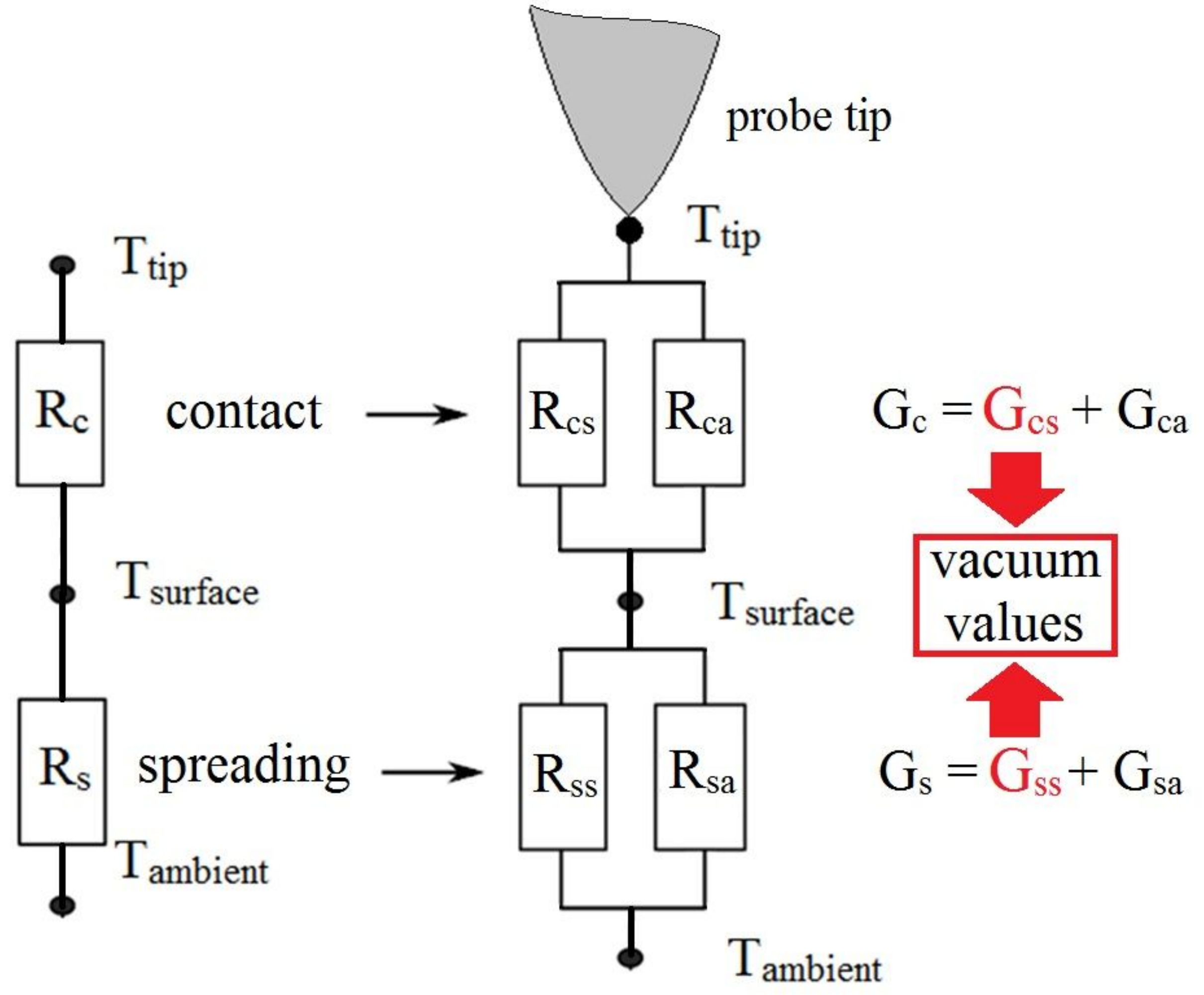
